\title{
Simulation and Experimental Study of the Rock Breaking Mechanism of Personalized Polycrystalline Diamond Compact Bits
}

\author{
Yu Jinping ${ }^{1, *}$, Zou Deyong ${ }^{1}$, Sun Yuanxiu ${ }^{2}$ and Zhang Yin ${ }^{3}$ \\ ${ }^{1}$ School of Petroleum Engineering, China University of Petroleum (East China), Qingdao, 266580, China \\ ${ }^{2}$ College of Petroleum Engineering, Liaoning Shihua University, Fushun, 113001, China \\ ${ }^{3}$ Department of Petroleum Engineering, University of Alaska Fairbanks, Fairbanks, Alaska, 99775, United States
}

Received 14 July 2020; Accepted 29 September 2020

\begin{abstract}
Rock breaking is a complex physical process that can be influenced by various factors, such as geometrical shape and cutting angle of rock breaking tools. Experimental study of the rock breaking mechanism of personalized bits is restricted due to long cycle and high cost. This study simulated the rock breaking mechanism of polycrystalline diamond compact (PDC) bit by combining finite element method and experiment. The simulation was performed to shorten the period and reduce the cost of studying the rock breaking mechanism of PDC bits. A rock breaking finite element model for sting cutters of personalized PDC bit was established to simulate the rock breaking process. The crack propagation pattern, dynamic stress of rock breaking, and rock breaking mechanism of sting cutters of personalized PDC bit were analyzed. The correctness of the simulation results was verified through experiments. Results demonstrate that the rock breaking load increases with the crack propagation in the fracture initiation and propagation stages, with the maximum tangential force of $1062.5 \mathrm{~N}$ and maximum axial force of $1850.0 \mathrm{~N}$. The load changes in a small range when the crack penetrates the rock, with the tangential force of 125.0-500.0 N and axial force of 375.0-875.0 N. The rock breaking mechanism of the sting cutters of bit is consistent with maximum tensile stress theory. The rock begins to break when the tensile stress of rock is $36.9 \mathrm{MPa}$. The sting cutters of personalized PDC bit have better wear resistance than the sting cutters of conventional bit. The average wear rates of personalized PDC and conventional bits are $1.74 \mathrm{E}-4$ and $2.1 \mathrm{E}-4 \mathrm{~mm} / \mathrm{m}$, respectively. This study serves as reference for shortening the study period of rock breaking mechanism, efficiently designing personalized PDC bit structure, reducing bit wear, and enhancing rock breaking efficiency.
\end{abstract}

Keywords: PDC bit, Rock breaking mechanism, Crack, Dynamic stress, Abrasive resistance

\section{Introduction}

Polycrystalline diamond compact (PDC) materials have been extensively used in oil drilling technology due to their excellent hardness, wear resistance, impact resistance, and rock breaking efficiency. With the increase in oil drilling area and the improvement of drilling technology, high requirements are raised for the performance of bits in terms of formation properties and drilling requirements. To improve the wear resistance, impact resistance, rate of penetration (ROP), and footage of PDC bits when drilling hard rocks, experts in oil and mechanical engineering fields worldwide have designed PDC bits with special characteristics in accordance with the properties of different formations [1-3].

However, the formations with complex lithology and high hardness require targeted performance of PDC bits in the drilling process with the gradual expansion of drilling area and the increasing complexity of drilling environment. Many personalized PDC bits are needed because of complex drilling technology and special rock properties. The performance of PDC bits must be improved to meet the requirements of different strata and advanced drilling technology. Studying the rock breaking mechanism of personalized PDC bits that adapt to different strata,

\footnotetext{
*E-mail address: eugene_yujp@126.com

ISSN: $1791-2377$ @ 2020 School of Science, HHU. All rights reserved.

doi:10.25103/iestr. 135.16
}

geometrical shape and structure of rock breaking tools, and cutting angle of cutting cutter is challenging.

Scholars have conducted simulations and experiments to study the influence of geometrical shape and cutting angle of personalized bits on their performance, especially wear resistance [4-7]. However, practical engineering problems, such as simulation of the rock breaking mechanism of cutter shape, geometrical shape and cutting angle of personalized bit, and efficient design of personalized bit with excellent wear resistance, are still found. Therefore, simulating the relationship between rock breaking mechanism and cutter shape of bit and determining the influence of cutter structure on rock breaking efficiency and wear resistance in bit research and development industry are needed.

This study numerically simulated the rock breaking process of sting cutters of personalized PDC bit by establishing a finite element model. The general process of crack initiation and rock development broken by sting cutters of personalized PDC bit was analyzed. The changes in rock stress state during the rock breaking process of personalized PDC bit were explored to reveal the rock breaking mechanism. This method provides important reference and engineering significance for efficiently designing PDC bits, thoroughly understanding the rock breaking mode by personalized PDC bit with sting cutters, shortening the research period of rock breaking mechanism, and improving rock breaking efficiency. 


\section{State-of-the-art}

Petroleum and mechanical engineering scholars have explored PDC bits suitable for different formations from various perspectives. Soares et al. [1] studied the rock cutting process of PDC bits through modelling and simulated the rock cutting process of different PDC bits moving in arc and straight directions. They concluded that arc cutting and straight line cutting have no influence on rock breaking but produce vibration. Although the rock breaking process of PDC bits was simulated, they focused on the influence of drilling parameters on the mechanical properties of bits. Zou et al. [2] designed a personalized PDC bit for special strata and obtained the power function law of rock breaking efficiency through experiments. However, the process of bit design and shape is extremely complicated. Although a personalized bit was designed, the design cycle was not shortened. Miyazaki et al. [3] discussed the performance of PDC bit when breaking rocks with different properties and the relationship between wear resistance and drilling parameters through experiments. They explored the method for efficiently using PDC bit. However, they focused on the application of bit rather than its design. Agostini and Sampaio [4] monitored and controlled the wear of PDC bit in the hard rock layer of ultra-deep well in real time and prolonged the service life of bit based on Bayesian probability neural network. However, they did not simulate rock breaking with PDC bit. Agawani et al. [5] introduced a multifunctional drill bit combining PDC and tungsten carbide insert. The proposed drill bit is applicable to heterogeneous carbonate formation due to its good impact resistance, and the ROP is twice than that of conventional drill bit. However, they did not introduce how to design and evaluate the drill bit. Abbas, and Musa [6] indicated that different formations need different PDC bits. They evaluated the performance of PDC bits in accordance with their wear resistance and verified the rationality of analyzing the wear resistance of PDC bits using Raman shift and Fourier transform infrared spectroscopy through experiments. The importance of designing individualized bits and the urgency of studying efficient rock breaking mechanism were analyzed. Mazen et al. [7] proposed a new mathematical model for predicting the performance of PDC bit, studied the influence of bit shape, bit hydraulics, and rock strength on the performance of PDC bit, and predicted bit wear. They related drilling parameters with the performance and wear of bit for the first time but focused on bit wear rather than rock breaking mechanism. Sun et al. [8] developed a novel directional PDC bit (right-angle drag PDC bit) through numerical simulation to address the serious wear of conventional PDC bit when drilling hard and multi-layered strata in coal mines. They conducted field test and achieved high rock breaking efficiency. Jing et al. [9] conducted numerical simulation and field tests to study the rock breaking process of PDC bit under different working conditions. Their study aimed to improve the rock breaking efficiency, but did not consider the relationship between bit structure and broken rock. The rock breaking mechanism was not analyzed through simulation. Huang et al. [10] proposed a rotating modular PDC bit and studied the variation rules of cutting load and MSE of rotating module element under different structural parameters, but the rotating modular of this PDC bit is instability and low service life. Wang et al. [11] established a 3D dynamic rock breaking model on 3D finite element software to measure the mechanical properties of rock and discussed the rock breaking law. However, they failed to provide the rock breaking mechanism by coupling drill and rock. Saksala et al. [12] conducted numerical simulation and experimental research on impact drill and performed dynamic simulation on rock damage through bit-rock interaction mode. Their study emphasized the relationship between impact velocity and rock breaking efficiency, but did not consider the rock breaking mechanism of bit. Niu et al. [13] evaluated the service life of PDC bit by conducting experiments and analyzing the structural characteristics and rock breaking mechanism of bit. However, they did not propose a new bit design method. Abbas [14] used finite element analysis and discrete element method to simulate and calculate bit wear by reviewing the studies of oil bit wear. The service life of PDC bit was explored. However, the relationship between rock breaking mechanism and bit structure was not considered. Wang et al. [15] explored the optimal cutter arrangement mode of PDC bit suitable for granite and hard sandstone through laboratory experiments. They investigated the relationship between cutter arrangement mode, service life, and ROP. The designed bit has strong pertinence, proving the importance of studying personalized bit. However, no personalized design method based on the rock breaking mechanism of bit is available. Sun et al. [16] developed a cutting-ploughing hybrid PDC bit to solve the short service life and low ROP of conventional PDC bit in heterogeneous hard stratum, thereby improving the impact resistance and rock breaking efficiency. Personalized PDC bit was studied, but the rock breaking mechanism was disregarded, and the development period of personalized PDC bit was long.

The above studies mainly focus on the service performance, mechanical properties, and wear resistance of PDC bits, and the design and performance of personalized bits. However, the study of personalized PDC bits through simulation is scarce, especially by simulating the process of drilling rock breaking. Few studies are reported on the rock breaking mechanism of personalized PDC bit on computer or shortening the design cycle. This study established a rock breaking finite element model of personalized PDC bit with sting cutters by combining finite element simulation of rock breaking mechanism and test. The rock breaking process of bit cutter was simulated. The crack propagation pattern and dynamic stress of rock breaking were analyzed on the basis of the crack propagation rock breaking model. The cutting rock breaking mechanism of personalized PDC bit with sting cutters was discussed, providing a foundation for determining the structure of personalized PDC bit cutter and evaluating the wear resistance. This simulation was completed on a computer, and a test was conducted to verify the rationality of theoretical analysis, thereby effectively eliminating the intermediate links and shortening the bit design cycle.

The remainder of this study is organized as follows. Section 3 describes the basic structure of the sting cutters of personalized PDC bits, and establishes the relevant rock breaking model and test model. Section 4 analyzes the fracture shape, dynamic stress, and rock breaking mechanism through the simulation calculation of breaking model. Combined with the test results, the relationship between the structure shape of personalized bit cutter and rock breaking principle is obtained. Section 5 summarizes this study and provides relevant conclusions. 


\section{Methodology}

\subsection{Basic structure of the sting cutters of personalized PDC bit}

The cutter of the personalized PDC bit is a cone structure, as shown in Fig. 1(a). In Fig. 1(b), the cutter profile of the PDC bit is a combined structure of cylinder and cone. The main body is high-quality carbon steel, and the cone part is covered with $2.0 \mathrm{~mm}$ polycrystalline diamond layer. The maximum thickness of the cone top is $3.0 \mathrm{~mm}$, the coneapex angle is $78^{\circ}$, and the radius of the cone top is $2.0 \mathrm{~mm}$. Other parameters are listed in Table 1. The bit cutter (Fig. 1) is modeled in accordance with the parameters in Table 1 .

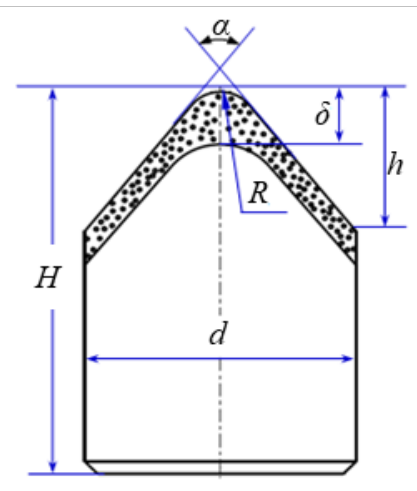

(a)

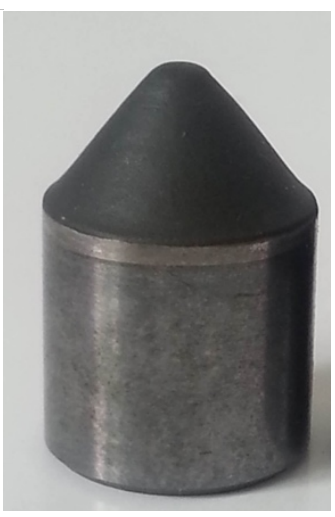

(b)
Fig. 1. Basic structure and picture of PDC sting cutters

Table 1. Structural parameters of the sting cutters of PDC bit

\begin{tabular}{l|l|l}
\hline $\begin{array}{l}\text { Cutter diameter } \\
d / \mathrm{mm}\end{array}$ & $\begin{array}{l}\text { Cutter height } \\
H / \mathrm{mm}\end{array}$ & $\begin{array}{l}\text { Cone apex } \\
\text { angle/ }^{\circ}\end{array}$ \\
\hline 14.8 & 21.8 & 78 \\
\hline \multirow{2}{*}{$\begin{array}{l}\text { Radius of cone } \\
\text { top/mm }\end{array}$} & Polycrystalline diamond layer \\
\cline { 2 - 3 } & Height & $\begin{array}{l}\text { Maximum thickness } \\
\delta / \mathrm{mm}\end{array}$ \\
\hline 2.0 & $h / \mathrm{mm}$ & 3.0 \\
\hline
\end{tabular}

\subsection{Finite element model of rock breaking by sting} cutters of personalized PDC sting cutters

The following assumptions are made in accordance with the relative stiffness of materials and the simulation environment to simplify the calculation and analysis:

(1) The influence of confining pressure, temperature, and drilling fluid on rock is neglected.

(2) The wear of the sting cutters is disregarded, and the contact part between bit cutter and rock is polycrystalline diamond, which has strong hardness and is regarded as a rigid body.

(3) The sting cutters of the personalized PDC bit spiral into the formation with a certain rotation radius. However, the motion of the sting cutters can be simplified to plane linear motion because the spiral angle is small.

(4) In the process of rock breaking, the cutting speed and the cutting depth of the sting cutters of the personalized PDC bit are changeless.

A 3D model of rock was established. The length of rock in the cutting direction should be approximately 10 times of the cutting depth to avoid the influence of boundary effect caused by rock size on unit stress. The shape of the breaking pit formed by the sting cutters of the personalized PDC bit was considered. The angle between the rock surface contacting with the sting cutters and the vertical line is $60^{\circ}$ (that is, the sting cutters presses to form a $120^{\circ}$ breaking pit), as shown in Fig. 2.

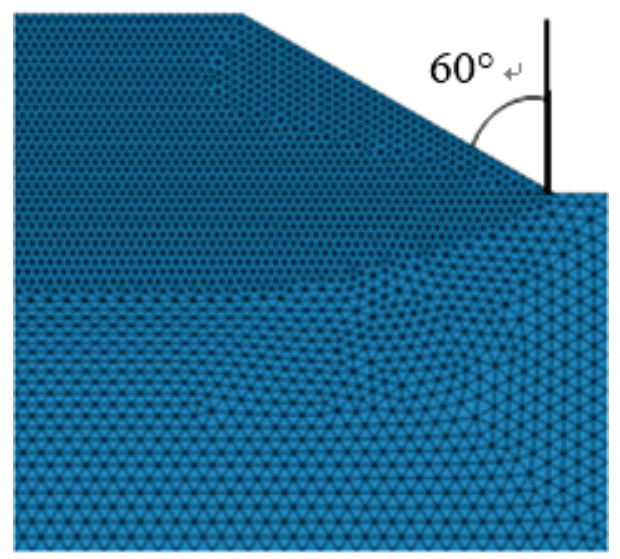

Fig. 2. Three-dimensional model of rock

Two grid division methods of the rock model are given in Fig. 3. The grids were divided with 3D solid 164 unit. A tetrahedral mesh was used to simulate the crack shape in the process of breaking, as shown in Fig. 3(a). The upper part was divided into small grids with a size of approximately 0.1 $\mathrm{mm}$, and the lower part was divided into large grids to save calculation time. The stress state can be calculated more accurately by using hexahedron grids rather than tetrahedron grids. The rock was divided into grids through sweeping, as shown in Fig. 3(b).

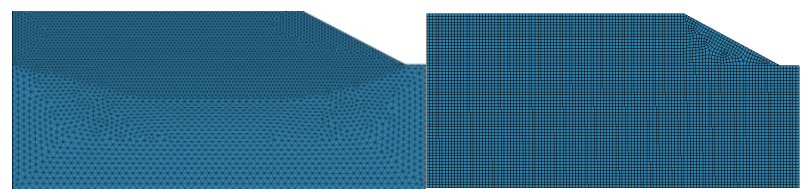

(a)

(b)

Fig. 3. Rock grids

The geometric model of the sting cutters is a conical structure. Its structural parameters are as follows: diameter of sting cutters $(14.8 \mathrm{~mm})$, diameter of taper top $(2.0 \mathrm{~mm})$, cone apex angle $\left(78^{\circ}\right)$, and total height $(20.0 \mathrm{~mm})$. The size of the conical part is changeless, and the cylindrical part can be adjusted. In the actual simulation and calculation process, the cutting part at the conical top was reserved because of the rigidity of the cutter structure, and other parts were reduced to save calculation time.

When dividing the grids of the sting cutters, the cutters were regarded as a rigid body (the type and size does not influence the solution result). Therefore, 3D solid 164 unit and free grid division technology were used to divide the cutters into tetrahedral grids. The geometric model and grids are presented in Fig. 4.

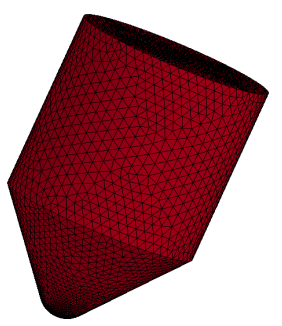

Fig. 4. Model and grids of sting cutter

The finite element model of the rock breaking with sting cutters was used to mainly study rock damage and breakage. 
The personalized PDC bit was regarded as a rigid body, and MAT_RIGID model was used for the bit cutter. The basic parameters in accordance with the material properties of bit cutter are as follows: density is $3500 \mathrm{~kg} / \mathrm{m}^{3}$, elastic modulus is $855 \mathrm{GPa}$, and Poisson's ratio is 0.077 [17].

This study used MAT_CSCM material model. The compressive strength of the rock based on the comparative test was determined to be $132 \mathrm{MPa}$. Other strength parameters were calculated by referring to relevant literature $[18,19]$ about the determination method of cap model parameters. The main rock parameters are listed in Table 2. In the simulation, the rock sample is sesame white granite, and some parameters of the rock sample are set to default values.

Table 2. Main parameters of rock material properties

\begin{tabular}{|c|c|c|c|c|}
\hline $\begin{array}{l}\text { Density } \\
\rho /\left(\mathrm{kg} / \mathrm{m}^{3}\right)\end{array}$ & $\begin{array}{l}\text { Shear modulus } \\
G / \mathrm{GPa}\end{array}$ & $\begin{array}{l}\text { Bulk modulus } \\
K / \mathrm{GPa}\end{array}$ & $\begin{array}{l}\text { Plastic volumetric } \\
\text { strain parameter } \\
W / \text { dimensionless }\end{array}$ & $\begin{array}{l}\text { Volume change rate } \\
\text { Parameter } \\
D_{1} / \mathrm{GPa}^{-1}\end{array}$ \\
\hline 2600 & 28 & 38.1 & 0.009 & 30 \\
\hline $\begin{array}{ll}\text { Volume change rate } \\
\text { parameter } \\
D_{1} / \mathrm{GPa}^{-1} & \end{array}$ & $\begin{array}{l}\text { Cap shape parameters } \\
R / \text { dimensionless }\end{array}$ & $\begin{array}{l}\text { Cap position parameter } \\
X_{0} / \mathrm{GPa}\end{array}$ & $\begin{array}{l}\text { Compressive meridian } \\
\text { strength parameter } \\
\alpha / \mathrm{GPa}\end{array}$ & $\begin{array}{l}\text { Compressive meridian } \\
\text { parameter } \\
\theta / \text { dimensionless }\end{array}$ \\
\hline 0 & 0.6 & 0.006 & 0.075 & 30 \\
\hline $\begin{array}{l}\text { Compressive meridian } \\
\text { parameter } \\
\lambda / \mathrm{GPa}\end{array}$ & $\begin{array}{l}\text { Compressive meridian } \\
\text { parameter } \\
\beta / \mathrm{GPa}^{-1}\end{array}$ & $\begin{array}{l}\text { Shear meridian parameter } \\
\alpha_{1} / \mathrm{GPa}\end{array}$ & $\begin{array}{l}\text { Shear meridian parameter } \\
\beta_{1} / \mathrm{GPa}^{-1}\end{array}$ & $\begin{array}{l}\text { Shear meridian parameter } \\
\theta_{1} / \text { dimensionless }\end{array}$ \\
\hline $70 \mathrm{E}-3$ & 8 & 0.068 & 7.8 & 0.02 \\
\hline
\end{tabular}

In the simulation of rock breaking, the linear velocity in $\mathrm{X}$ direction was $2.0 \mathrm{~m} / \mathrm{s}$, and the linear displacement in the other two directions and the angular displacement in all directions were constrained, as shown in Fig. 5(a). The rock finite element model in stress analysis (Fig. 3(b)) was taken as an example. The linear displacement in $\mathrm{Y}$ direction at the rock bottom and $\mathrm{X}$ direction at the rock front was constrained, and the constraint position of linear displacement in $\mathrm{Z}$ direction changed with the simulation. In

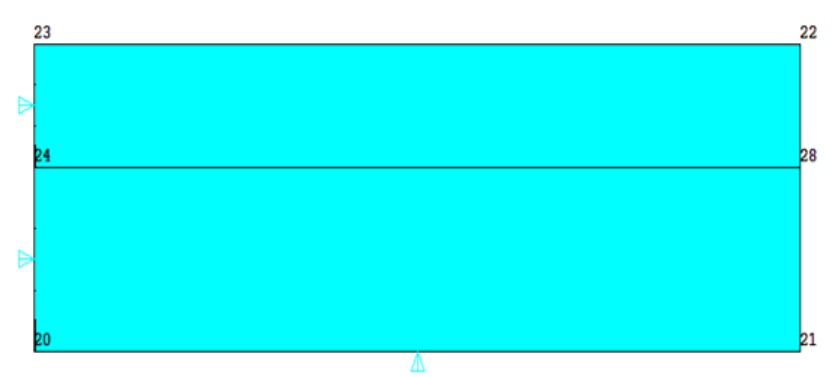

(a)

Fig. 5. Boundary conditions of the rock model

Other load settings are as follows: (1) downward gravity acceleration was applied to the rock through stress relaxation. In the simulation, the cutting depth of the sting cutters of the personalized PDC bit was $2.0 \mathrm{~mm}$. The simulation solution time, rock breaking stress, and historical variable output were set.

\subsection{Rock breaking model of sting cutters based on crack propagation}

In accordance with the crack propagation simulation of conventional PDC bit cutter slab cutting, this study investigated the change in crack shape on the plane composed of cutting speed and cutting depth. The rock structure parameters and boundary treatment method were treated as a plane strain problem. The size of the rock in $\mathrm{Z}$ direction was roughly equal to the diameter of the top cutting part of bit cutter. The linear displacement at the rock this way, the angular displacement in all directions was constrained.

Nonreflective boundary was applied to the bottom and two sides of the rock, as shown in Fig. 5(b). In stress analysis (Fig. 3(b)), nonreflective boundary condition can prevent the artificial stress wave generated on the boundary from re-entering into the model. It can also avoid the error caused by influence on stress calculation result and express the semi-infinite stratum domain by finite field in finite element software.

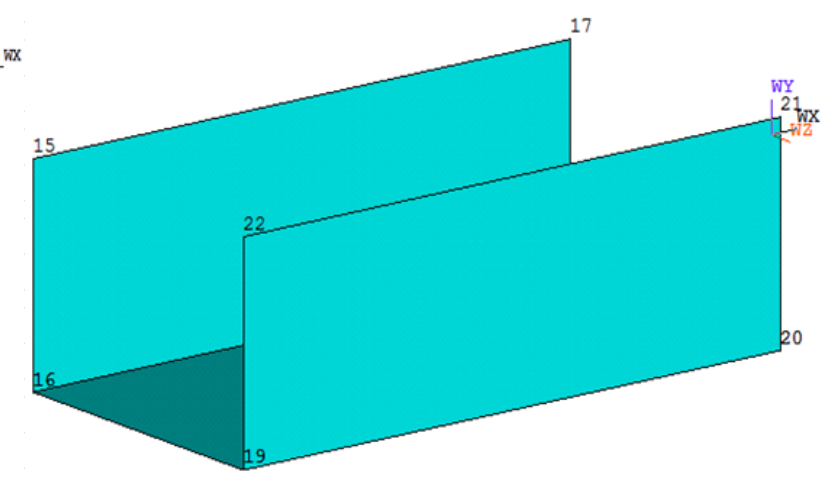

(b)

bottom in $\mathrm{Y}$ direction, linear displacement on the two sides and at front of rock in $\mathrm{Z}$ and $\mathrm{X}$ directions, and angular displacement in all directions were constrained. The contact between the cutting cutter and the rock was defined as single-sided contact, and the contact between rock erosion units was erosion surface-to-surface contact. The geometric model of rock and bit cutter used to simulate crack propagation is presented in Fig. 6 .

The sting cutters of the personalized bit with tip radius of $2.0 \mathrm{~mm}$, top rake of $17^{\circ}$, rock cutting depth of $2.0 \mathrm{~mm}$, and cutting speed of $2.0 \mathrm{~m} / \mathrm{s}$ were used as an example. LSDYNA was utilized to simulate the crack shape during rock breaking by using the sting cutters of the personalized PDC bit, and the data were collected. The horizontal force (shear force) and the axial force (WOB) were directly outputted on post processing software LS-PREPOST. 


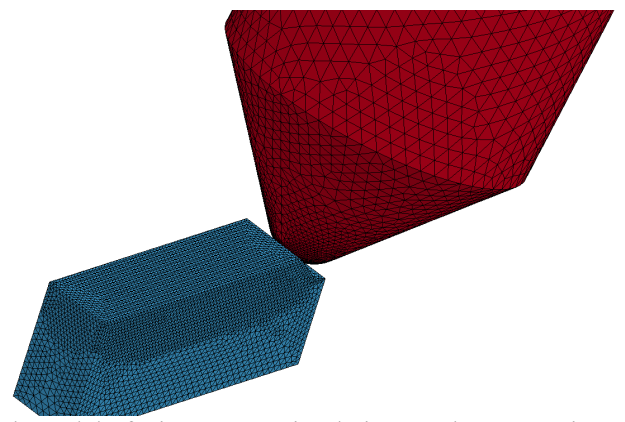

Fig. 6. Rock model of sting cutters simulating crack propagation

The simulation of crack propagation reveals the complete rock breaking process of crack initiation, propagation, and initiation. However, the rock breaking mechanism of bit cutter is described with the changes in dynamic stress during rock breaking. The dynamic stress of the sting cutters of the personalized PDC bit was simulated and calculated, and the length/cutting depth and width/cutting width of the rock were kept at 10: 1 . The erosion surface of the rock and the sting cutters of the personalized PDC bit were set as the surface contact. The top rake was $17^{\circ}$, the cutting depth was $2.0 \mathrm{~mm}$, and the cutting speed was $2.0 \mathrm{~m} / \mathrm{s}$. The finite element model for the rock cut with the sting cutters of the personalized PDC bit is shown in Fig. 7. Only the cutting part was reserved in the actual solution process because of the rigidity of the bit to save calculation time.

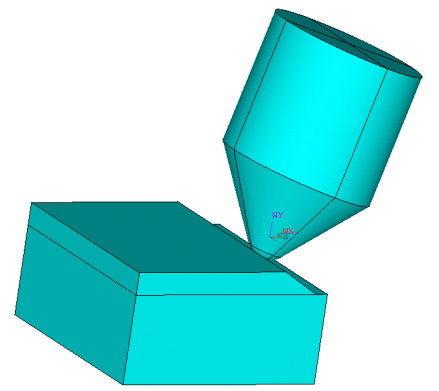

Fig. 7. Rock cutting model of sting cutters calculating stress

3.4 Experimental verification model of wear resistance of the sting cutters of the personalized PDC bit

The wear resistance of the sting cutters of the PDC bit was tested on a PDC performance test system to compare the reliability of the simulation results, as shown in Fig. 8. The rock sample was sesame white granite, with drillability grade of 8.3. The sting cutters of the personalized PDC bit are shown in Fig. 1(b)) and 1613 compact (cylindrical cutter). The parameters are as follows: rotating speed (100 $\mathrm{rpm})$, depth $(0.26 \mathrm{~mm})$, and radial feed rate $(3 \mathrm{~mm} / \mathrm{rev})$. The termination condition is the machine automatically stops running when the load is greater than $6000 \mathrm{~N}$.

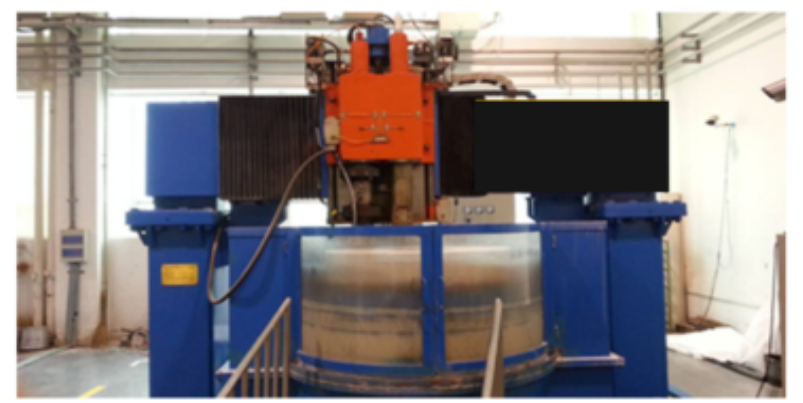

Fig. 8. Physical drawing of PDC performance test system

\section{Result analysis and discussion}

4.1 Analysis of fracture shape during rock breaking of the sting cutters of the personalized PDC bit

The sting cutters with tip radius of $2.0 \mathrm{~mm}$, top rake of $17^{\circ}$, rock cutting depth of $2.0 \mathrm{~mm}$, and cutting speed of $2 \mathrm{~m} / \mathrm{s}$ were used as an example. LS-DYNA was utilized to simulate the crack shape during rock breaking by the sting cutters of the personalized PDC bit, and the data were collected. The horizontal force (shear force) and the axial force (WOB) were directly outputted on post processing software LS-PREPOST. The relationship between load and time during rock breaking was drawn, as shown in Fig. 9.

In Fig. 9, the curve describes the change in axial and tangential forces of the sting cutters with time. The fracture expansion diagram from $t_{0}$ to $t_{4}$ was extracted, as shown in Fig. 10. Combined with the output axial force and tangential force in post processing, the rock breaking process of the sting cutters of the personalized PDC bit is described as follows:

(1) Initial contact stage between sting cutters and rock $\left(0-t_{0}\right)$ : The sting cutters begin to contact with the rock, axial and tangential forces gradually increase from zero, rock cracks have not occurred, and rock deformation belongs to elastic deformation, as shown in Fig. 10(a). Cracks occur at $t_{0}$.

(2) Initiation stage of rock crack $\left(t_{0}-t_{1}\right)$ : From $t_{0}$ to $t_{1}$, the tangential and axial forces increase, and cracks initiate and develop in the rock with the continuously drilling of sting cutters into the rock. As shown in Fig. 10(b), the cracks initiated at $t_{1}$ further develop

(3) Crack propagation stage $\left(t_{1}-t_{2}\right)$ : From $t_{1}$ to $t_{2}$, the sting cutters further drills into the rock, and the tangential and axial forces increase to the maximum values, reaching 1062.5 and $1850.0 \mathrm{~N}$, respectively. The increasing tangential force makes the cracks gradually extend to the vicinity of the free surface of the rock. The micro cracks occur in the area near the contact surface between the sting cutters and the rock and develop into the rock, as shown in Fig. 11.

(4) Crack penetration stage $\left(t_{2}-t_{3}\right)$ : From $t_{2}$ to $t_{3}$, the cracks penetrate as they develop toward the free surface of the rock, forming a large lithic fragment stripped from the rock. The tangential and axial forces decrease rapidly. Fig. $10(d)$ shows the nephogram of rock crack penetration.

(5)Crack spreading stage $\left(t_{3}-t_{4}\right)$ : From $t_{3}$ to $t_{4}$, the cracks initiate rapidly. The tangential force changes from $125.0 \mathrm{~N}$ to $500.0 \mathrm{~N}$, and the axial force changes from $375.0 \mathrm{~N}$ to $875.0 \mathrm{~N}$. This condition results in the large rock lithic fragment stripped from the rock by the sting cutters at $t_{4}$, as shown in Fig. 10(e). The sting cutters of PDC bit continues cutting and contacts with the rock. The rock breaking process of (1)-(4) is repeated. The tangential and axial forces gradually increase at $t_{4}\left(t_{0}\right.$ of the next rock breaking period), and the next cutting process begins).

4.2 Analysis of dynamic stress of the sting cutters of the personalized PDC bit during rock breaking process

The nephogram of the maximum shear stress and maximum principal stress at three important moments of rock breaking process was extracted, as shown in Fig. 11. Combined with the analysis of crack propagation formed in Section 4.1, the rock breaking process of the sting cutters of the personalized 
PDC bit is divided into three stages: elastic deformation compaction, sting cutter drilling, and extreme tensile stress extension stages, which are analyzed as below.

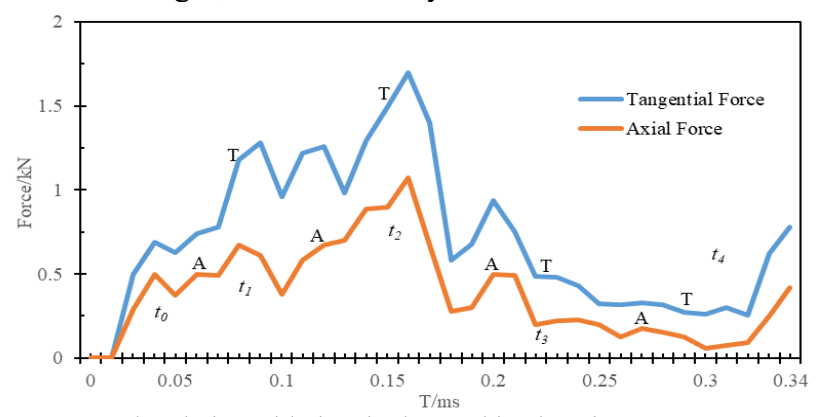

Fig. 9. Load variation with time in the crushing by sting cutters

(1) Compaction stage of elastic deformation $\left(0-t_{0}\right)$ : At $t_{0}$, the rock below the personalized PDC bit was compressed by the sting cutters and elastically deformed when the sting cutters of the personalized PDC bit contacted with the rock. A compressive stress concentration area appeared below the top of the sting cutters (Fig. 11(a)). A rock "dense core" was formed under the sting cutters and acted as a stress transmission medium to the surrounding rock. In Fig. 11(b), the rock was subjected to extremely strong shear in the 3D compression area. The tensile stress shows an annular region distributed around the compression shear region. Figs. 11(a) and 11(b) show the stress nephograms at $t_{0}$.
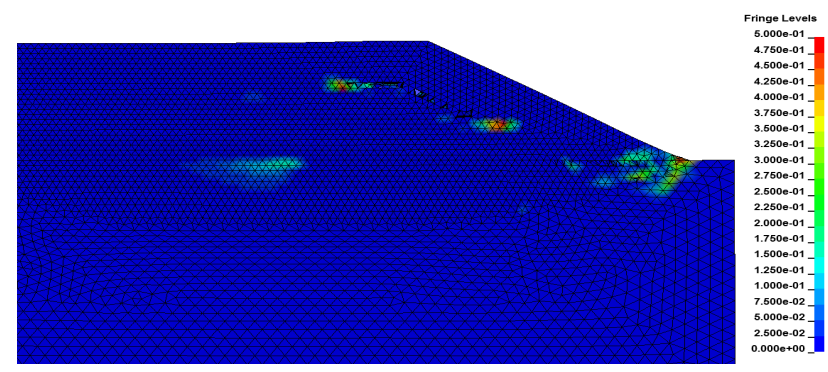

(a) $\left(t_{0}\right) \mathrm{T}=0.08 \mathrm{~ms}, \mathrm{~L}=0.16 \mathrm{~mm}$
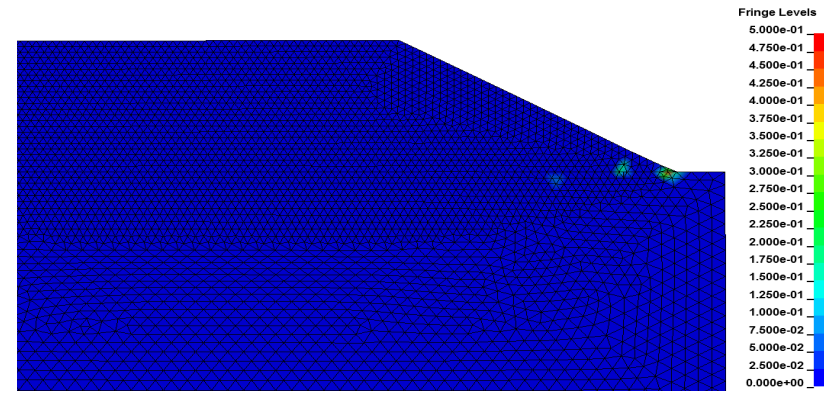

(b) $\left(t_{1}\right) \mathrm{T}=0.10 \mathrm{~ms}, \mathrm{~L}=0.20 \mathrm{~mm}$
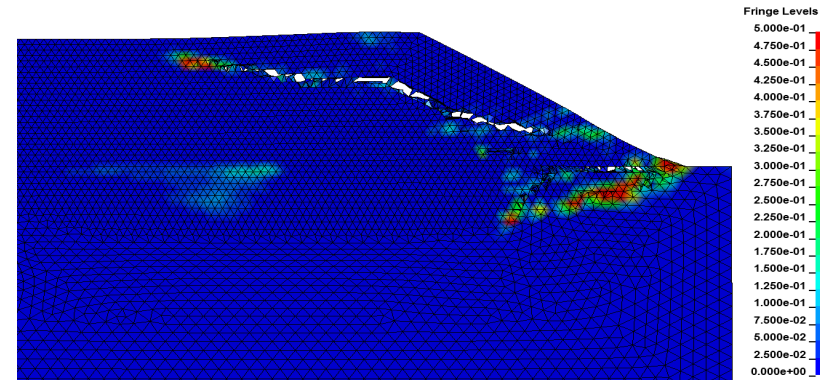

(c) $\left(t_{2}\right) \mathrm{T}=0.15 \mathrm{~ms}, \mathrm{~L}=0.30 \mathrm{~mm}$

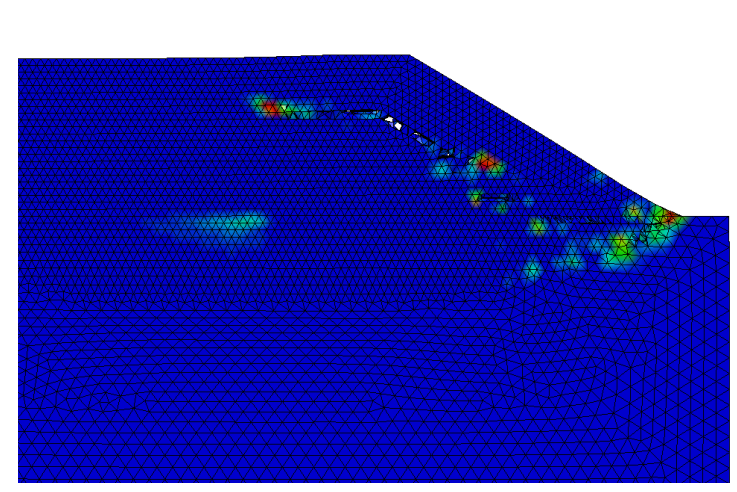

$5.0000 \cdot 01$ 5.750e-01] $4.500 \mathrm{e}-01$
$4.250 \mathrm{e}-01$ $4.0000 \cdot 01$ $3.7500-01-$
$3.500 e-01$ $3.2500-01$

(d) $\left(t_{3}\right) \mathrm{T}=0.18 \mathrm{~ms}, \mathrm{~L}=0.36 \mathrm{~mm}$
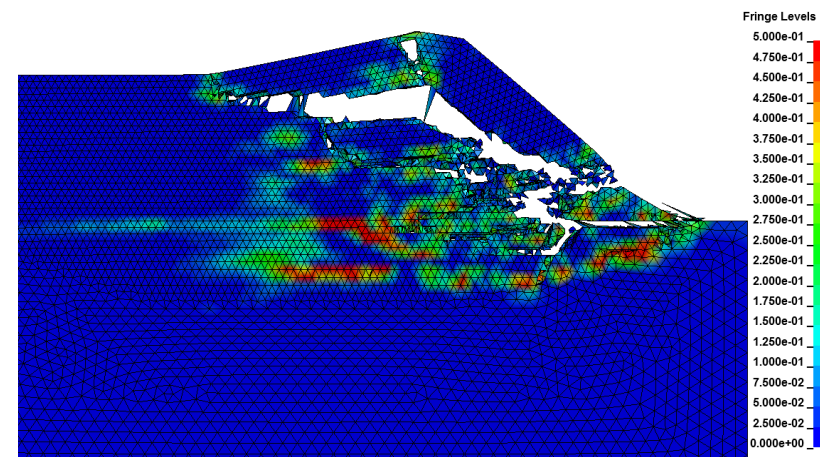

(e) $\left(t_{4}\right) \mathrm{T}=0.28 \mathrm{~ms}, \mathrm{~L}=0.56 \mathrm{~mm}$

Fig. 10. Contour nephogram of rock cracks at different times

(2) Drilling stage of sting cutter $\left(t_{0}-t_{1}\right)$ : The rock under the sting cutters of the personalized PDC bit was damaged by compression and shear, and a breaking pit was formed. The front end face of the sting cutters contacted with the rock through drilling. A main stress concentration area occurred in the normal direction of the rock contact surface due to extrusion. The first main stress in the stress concentration area was tensile stress, which was obviously higher than that in the surrounding area of the rock (Fig. 11(c)). The shear stress was distributed annularly in the rock. The closer it is to the tapered cutter, the greater its shear stress value (Fig. 11(d)).

(3) The extension stage of extreme tensile stress $\left(t_{1}-t_{2}\right)$ : The sting cutters of the personalized PDC bit further drilled into the rock and cut the rock. This condition caused the tensile stress concentration area in the rock gradually expand to the free surface of the rock, and the tensile stress increased. As shown in Fig. 11(e), the tensile stress in a certain area outside the contact surface of the sting cutters was the maximum at $t_{2}$, reaching $36.9 \mathrm{MPa}$. This stress gradually changed into compressive stress, and the compressive stress on the contact surface of the sting cutters was the maximum, reaching $132.5 \mathrm{MPa}$. The shear stress on the contact surface of the sting cutters was $119.6 \mathrm{MPa}$. The distribution law of shear stress is the same as that in 4.2(2). With the contact surface between the sting cutters and the rock as the core area, the shear stress in the rock decreased from the contact surface to the interior of the rock, as shown in Fig. 11(f). 


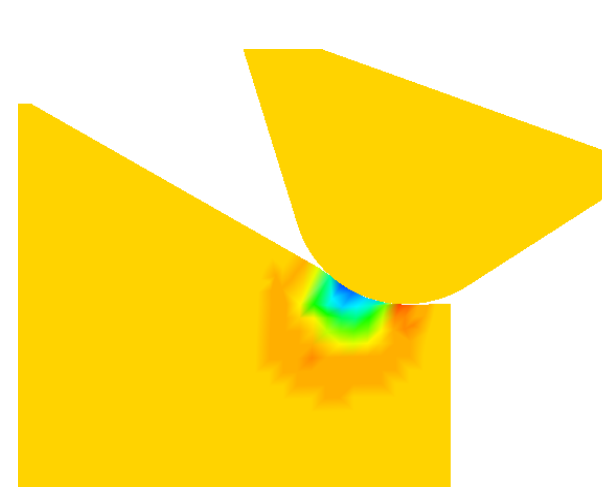

(a) Maximum principal stress at $t_{0}$

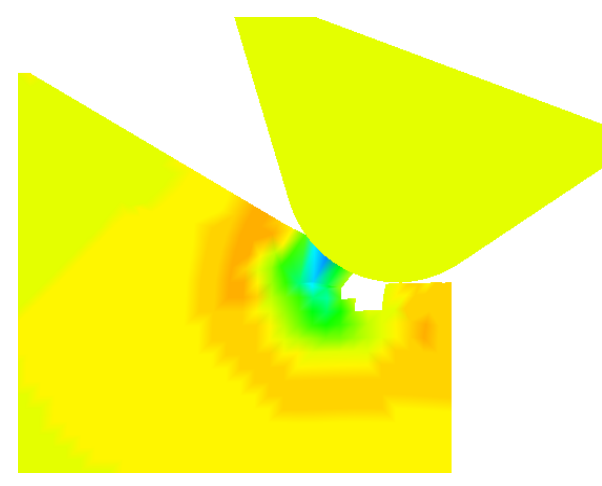

(c) Maximum principal stress at $t_{1}$

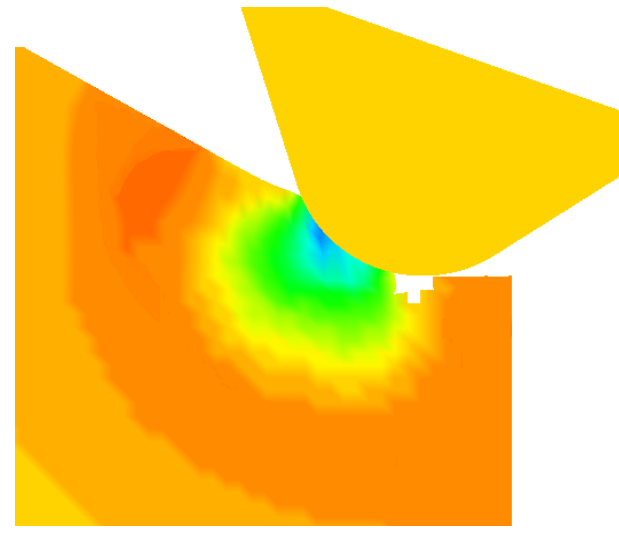

(e) Maximum principal stress at $t_{2}$

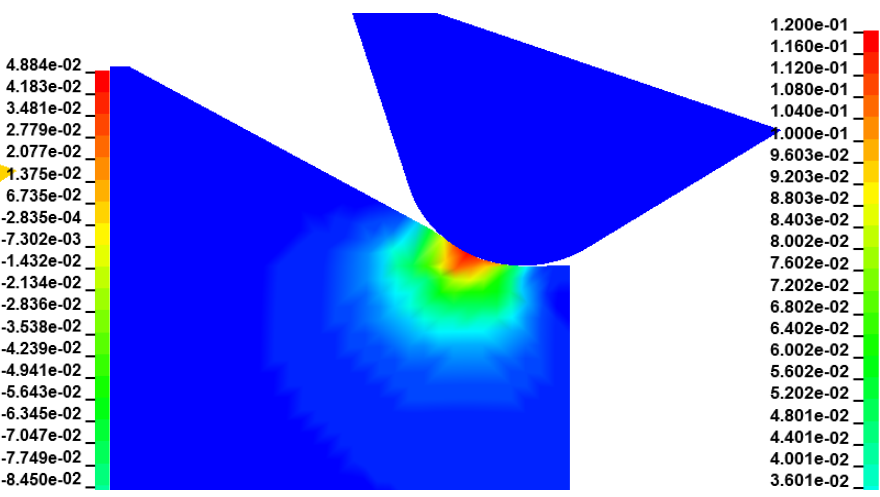

(b) Maximum shear stress at $t_{0}$

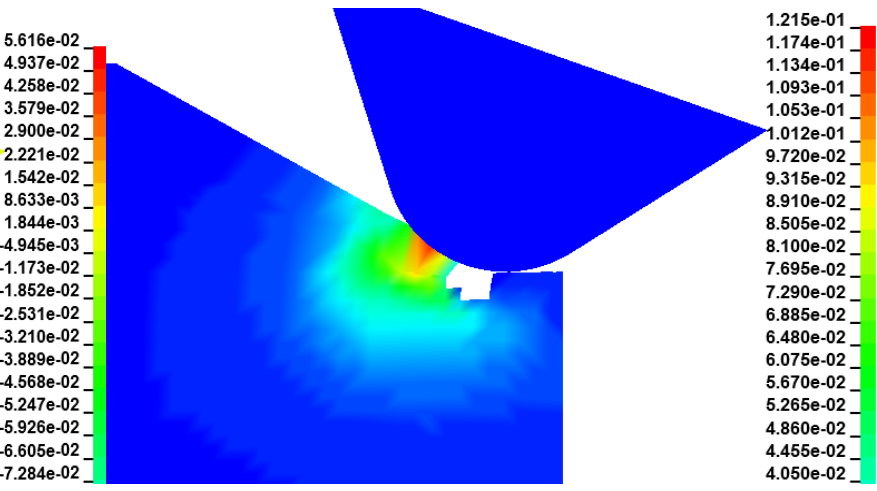

(d) Maximum shear stress at $t_{1}$

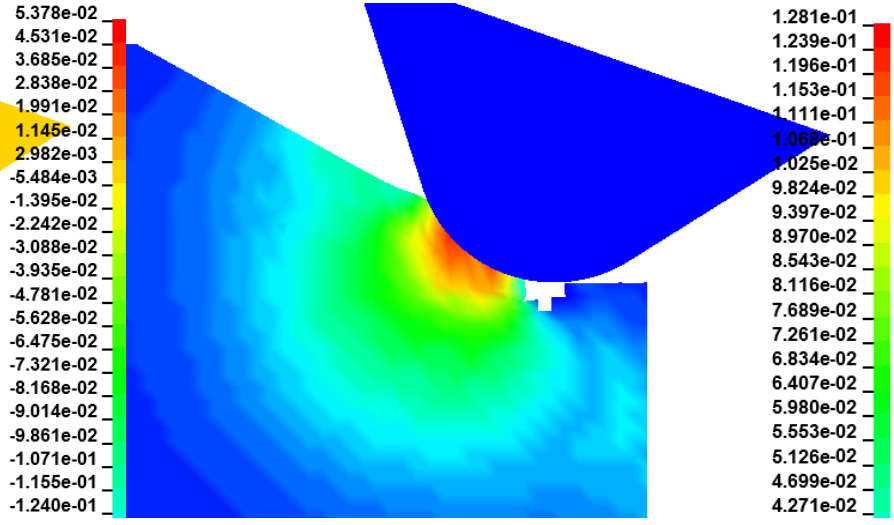

(f) Maximum shear stress at $t_{2}$

Fig. 11. Dynamic stress nephogram (stress unit: $10^{9} \mathrm{~Pa}$ ) of the rock broken by sting cutters

\subsection{Analysis of rock breaking mechanism of the sting cutters of the personalized PDC bit}

Rock breaking meets maximum tensile stress and shear strength theories. Different rock breaking tools correspond to different stress state distributions. The rock breaking mechanisms of conventional PDC bit and personalized PDC bit are compared.

Fig. 12 shows the initial crack and stress nephogram when sting cutter cuts the rock. The tip of the sting cutter contacts with the rock after sting cutter drills into rock, as shown in Fig. 12(a). The concentration area of main stress appears in the normal direction of the contact surface (tensile stress). When the extreme value of the tensile stress reaches the rock breaking stress, the rock is damaged, and cracks are initiated. The crack shape is shown in Fig. 12(b). The crack shape and the crack initiation position are consistent with the position of the maximum principal tensile stress. 


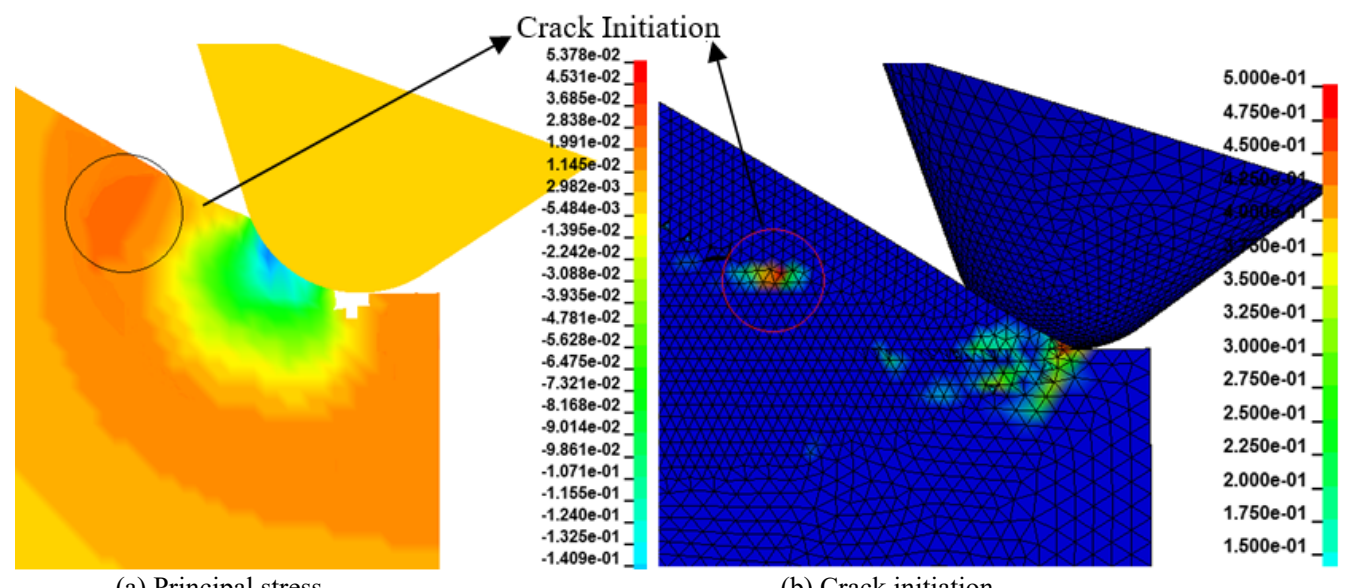

(a) Principal stress

(b) Crack initiation

Fig. 12. Rock breaking crack and stress nephogram of sting cutters

The cylindrical cutter of conventional PDC bit is commonly used in oil drilling and it cuts rocks with caster angle. In accordance with the same modeling standard and analysis method in 3.2 , the caster angle of conventional PDC cutter is $15^{\circ}$, the cutting depth parameter is $2.0 \mathrm{~mm}$, the cutting speed is $2.0 \mathrm{~m} / \mathrm{s}$, and the breaking pit formed by pressing into the rock is $120^{\circ}$. The crack propagation state and the corresponding maximum shear stress are shown in Fig. 13.

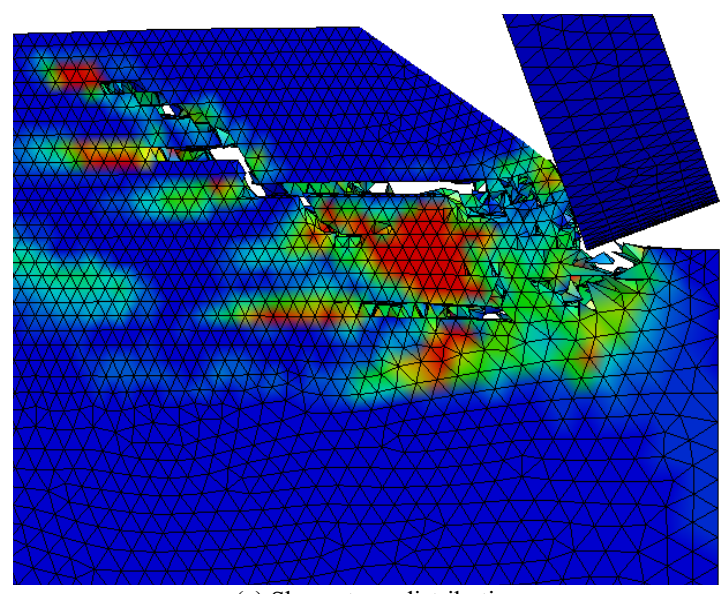

(a) Shear stress distribution

Fig. 13. Crack morphology and maximum shear stress of circular cutters

The rock breaking mechanism of the sting cutters of the personalized PDC bit and the cylindrical cutter of the conventional PDC bit are different. Conventional PDC bit with cylindrical cutter breaks the rock by shearing, forming large lithic fragments, and the rock breaking efficiency is high. However, large shear force is required due to the high shear strength of the rock, causing serious wear on the bit. The sting cutter of the personalized PDC bit breaks the rock with the maximum tensile stress, and the lithic fragments are small. However, the sting cutter can break the rock easily because the tensile strength of the rock is lower than the shear strength. The rock breaking efficiency is high, and the wear resistance of the bit can be improved because of the small load.

Table 3. Comparison of wear test results

\begin{tabular}{l|l|l|l|l|l|l}
\hline cutter shape & $\begin{array}{l}\text { Number } \\
\text { of turns }\end{array}$ & $\begin{array}{l}\text { Wear height } \\
(\mathrm{mm})\end{array}$ & $\begin{array}{l}\text { Total distance } \\
(\mathrm{m})\end{array}$ & $\begin{array}{l}\text { Wear rate } \\
(\mathrm{mm} / \mathrm{m})\end{array}$ & Description of WA & Remarks \\
\hline Sting cutters & 34 & 1.4 & 8100 & $1.73 \times 10^{-4}$ & $\begin{array}{l}\text { Even worn (EW) without } \\
\text { disintegrate }\end{array}$ & $\begin{array}{l}\text { The loading force reaches the } \\
\text { upper limit }\end{array}$ \\
\hline Sting cutters & 36 & 1.5 & 8576 & $1.75 \times 10^{-4}$ & EW without disintegrate & The loading force reaches the \\
\hline
\end{tabular}

In accordance with the shear stress distribution in Fig. 13(a), the extreme value zone of shear stress in the process of rock breaking of the cylindrical cutter of the conventional PDC bit is strip-shaped and distributed in the normal direction of the contact surface between the cutter edge and the rock. This condition is consistent with the crack initiation position and direction during rock breaking. As shown in Fig. 13(b), the crack first extends horizontally in the cutting direction and then develops to the free surface of the rock during rock breaking, forming large lithic fragments.

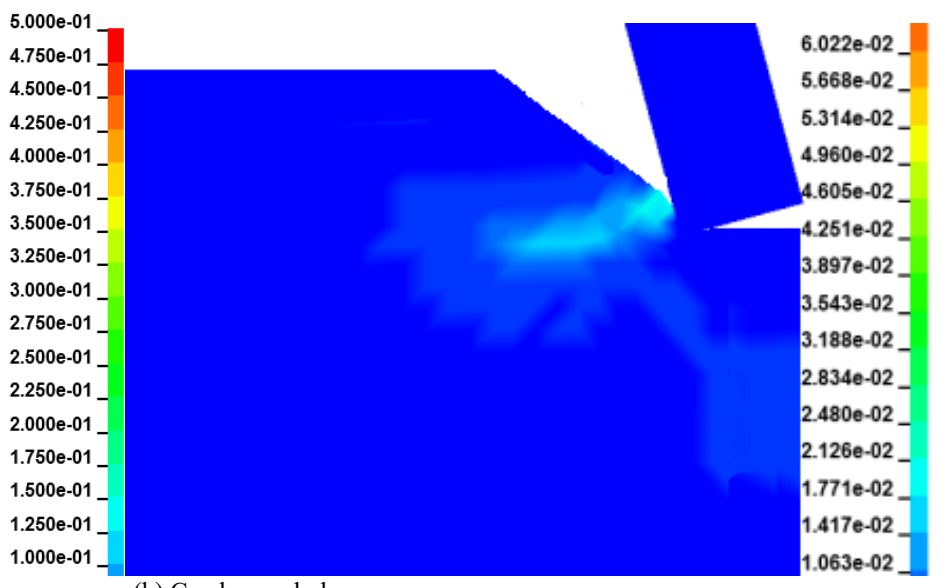

(b) Crack morphology

4.4 Test analysis of wear of the sting cutters of the personalized PDC bit

The performance of the sting cutters of the personalized PDC bit was analyzed through wear test, which corresponded to the simulation. The used sting cutters are shown in Fig. 1(b).

The wear of two sting cutters and PDC was tested on the basis of the same parameters. The data are shown in Table 3. The worn area (WA) shapes of the sting cutter (two samples) of the personalized PDC bit and the cylindrical cutter (one sample) are shown in Fig. 14. 


\begin{tabular}{l|l|l|l|l|l|l}
\hline & & & & & upper limit \\
\hline PDC & 40 & 2.0 & 9529 & $2.1 \times 10^{-4}$ & EW without disintegrate & \\
\hline
\end{tabular}

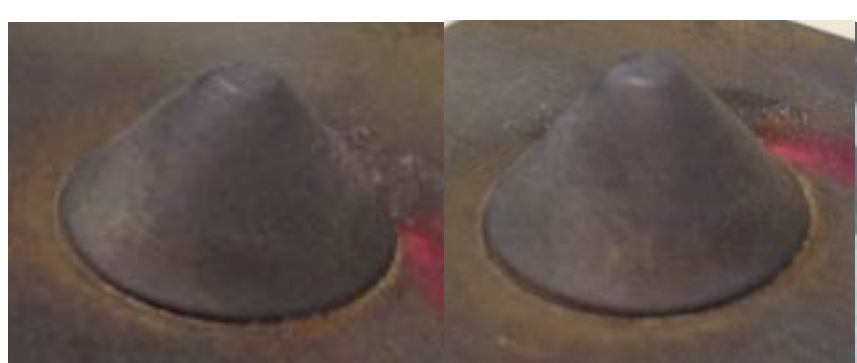

(a) 34 turns sting cutter

(b) 36 turns sting cutter

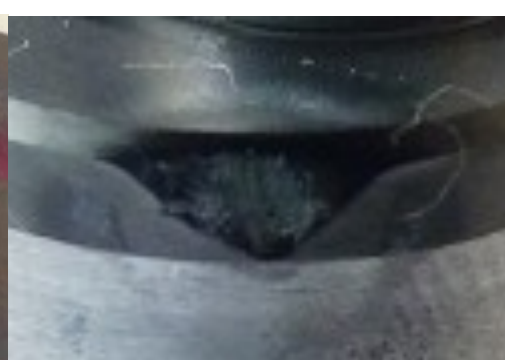

(c) 40 turns PDC

Fig. 14. Picture of the WA of cutters

The average wear rate of the sting cutters of the personalized PDC bit is $1.74 \times 10^{-4} \mathrm{~mm} / \mathrm{m}, \mathrm{EW}$ without disintegrate under the action of upper load limit by analyzing the experimental results in Table 3. The wear rate of 1613 PDC under low load is $2.1 \times 10^{-4} \mathrm{~mm} / \mathrm{m}$, which is obviously greater than that of the sting cutter of the personalized PDC bit, and the cutter is seriously worn (Fig. 14(c)).

\section{Conclusions}

This study combined finite element simulation and experiment to study the rock breaking mechanism of personalized PDC bits. The combined process was performed to analyze the relationship between bit structure and rock breaking mechanism, shorten the study period of the rock breaking mechanism of personalized PDC bits, and reduce the development cost. A finite element model for rock breaking of personalized PDC bits was established to simulate the rock breaking process of bit cutter. The crack propagation form and the dynamic stress of rock breaking were analyzed on the basis of the crack propagation rockbreaking model. The conclusions are summarized via comparison between the simulation and test results of PDC bit as follows:

(1) The process of rock breaking with sting cutters is divided into two stages: crack initiation and crack propagation stages. A nonlinear periodic relationship is found between rock breaking load and rock breaking time. The load increases nonlinearly from the contact between the sting cutter and rock to crack initiation and propagation. It reaches the maximum after crack propagation and decreases nonlinearly from crack penetration to rock breaking. The load is the smallest when the rock is broken.

(2) A negative correlation is found between bit cutter structure and rock breaking load. The more reasonable the PDC bit cutter structure is, the smaller the rock breaking load.

(3) The sting cutters of the personalized PDC bit have reasonable structure, and their wear resistance is better than that of the conventional bit.

This study provided a new understanding of the rock breaking mechanism of sting cutters of the personalized PDC bit by combining theoretical study and laboratory tests. A finite element model of rock breaking by sting cutters was established, which was simplified and applicable to the field. The proposed model has important reference value for shortening the study period of rock breaking mechanism, efficiently designing reasonable structure of personalized PDC bit, and improving bit wear resistance and rock breaking efficiency. Although this method can be used to simply and efficiently simulate and analyze the rock breaking mechanism, engineering verification is needed to apply it to engineering design. In future study, the proposed method will be continuously improved by accumulating experience.

\section{Acknowledgements}

This work was supported by the 13th Five Year Plan of Major National Special Projects of China (Grant No. 2016ZX05003-004-006).

This is an Open Access article distributed under the terms of the Creative Commons Attribution License

\section{References}

1. Soares, C., Daigle, H., Gray, K., "Finite element modelling of rock mass cutting by cutters for PDC drill bits". Petroleum Exploration and Development, 42(6), 2015, pp. 888-892.

2. Zou, D. Y., Xu, C. K., Yi, Y., Chen, X. P., Yu, J. P., "An experimental study on PDC bit's cutter parameters and formation adaptability". Natural Gas Industry, 37(9), 2017, pp. 85-90.

3. Miyazaki, K., Ohno, T., Karasawa, H., Imaizumi, H., "Performance of polycrystalline diamond compact bit based on laboratory tests assuming geothermal well drilling". Geothermics, 80, 2019, pp. 185-194.

4. Agostini, C. E., Sampaio, M. A., "Probabilistic neural network with Bayesian-based, spectral torque imaging and deep convolutional autoencoder for PDC bit wear monitoring". Journal of Petroleum Science and Engineering, 193, 2020, pp. 107434.
5. Agawani, W., Al-Enezi, D. R., Pandya, M., Gupta, P., Abdelhamid, A., Al-Habib, H., El-Touny, S., "Engineered hybrid drill bit technology doubles drilling performance in impact-prone carbonates heavy oil application". In: Proceedings of SPE International Heavy Oil Conference and Exhibition, Kuawait City, Kuwait: Society of Petroleum Engineers, 2018.

6. Abbas, R. K., Musa, K. M., "Using Raman shift and FT-IR spectra as quality indices of oil bit PDC cutters". Petroleum, 5, 2019, pp. 329-334.

7. Mazen, A. Z., Mujtaba, I. M., Hassanpour, Rahmanian, A., N., "Mathematical modelling of performance and wear prediction of PDC drill bits: Impact of bit profile, bit hydraulic, and rock strength". Journal of Petroleum Science and Engineering, 188, 2020, pp. 106849. 
8. Sun, R. J., Ju, P., Shi, Z. J., "Simulation study of new directional drilling PDC bit used in coal mine". Geosystem Engineering, 20(3), 2017, pp. 142-148.

9. Jing, Y. H., Yuan, X. W., Jiang, L., Zhang, H., Ni, H. J., "Numerical simulation and field experimental study on rock breaking in high speed rotating percussion drilling". Journal of China University of Petroleum, 43(1), 2019, pp. 75-80.

10. Huang, K. L., Yang, Y. X., Liu, Y., Zhong, Y. P., Ren, H. T., "Study on rock breaking mechanism of PDC bit with rotating module". Journal of Petroleum Science and Engineering, 192, 2020, pp. 107312.

11. Wang, X., Liu, Z. Y., Qu, S. N., Su, C., "Research on rock breaking simulation of PDC bit under rock property parameters in Weibei Oilfield”. China Energy and Environmental Protection, 40 (09), 2018, pp. 99-103.

12. Saksala, T., Gomon, D., Hokka, M., Kuokkala, V., "Numerical and experimental study of percussive drilling with a triple-button bit on Kuru granite". International Journal of Impact Engineering, 72, 2014, pp. 56-66.

13. Niu, S. W., Zheng, H. L., Yang, Y. X., Chen, L., "Experimental study on the rock-breaking mechanism of disc-like hybrid bit". Journal of Petroleum Science and Engineering, 161, 2018, pp. 541550 .
14. Abbas, R. K., "A review on the wear of oil drill bits (conventional and the state of the art approaches for wear reduction and quantification)". Engineering Failure Analysis, 90, 2018, pp. 554584.

15. Wang, B., Li, J., Zou, D. Y., Yang, H. W., Wang, K., "Design and application of a PDC hybrid drill bit with impregnated diamond insert for the hard formation with strong abrasivity". Special Oil Gas Reservoirs, 25(01), 2018, pp. 169-174.

16. Sun, Y. X., Zou, D. Y., Guo, Y. L., Chen, X. P., Yi, Y., "Design and field application of plow-cutting PDC bit". Oil Drilling \& Production Technology, 38(1), 2016, pp. 53-56.

17. Xu, G., Chen, F., Ma, C. D., Xu, G. P., "Lab test of PCD's Youn's modulus and Poisson's ratio". Petroleum Drilling Techniques, 37(3), 2009, pp. 63-65

18. Jiang, H., He, S. H., Wang, J. J., "Parameters determination of elasto-plastic damage cap model for concrete materials". Journal of Vibration and Shock, 31(15), 2012, pp. 132-139

19. Zhang, F. G., Li, E. Z., "A method to determine the parameters of the model for concrete impact and damage". Journal of Ballistics, 13(4), 2001, pp. 12-23. 